\title{
Guidelines
}

European Thyroid Journal
Eur Thyroid J 2019;8:173-185

DOI: $10.1159 / 000500881$
Received: January 8, 2019

Accepted after revision: April 29, 2019

Published online: July 4, 2019

\section{European Thyroid Association Guidelines on the Management of Thyroid Dysfunction following Immune Reconstitution Therapy}

\author{
Ilaria Muller ${ }^{a}$ Carla Moran $^{b}$ Beatriz Lecumberric ${ }^{c}$ Brigitte Decallonne ${ }^{d}$ \\ Neil Robertson ${ }^{e}$ Joanne Jones ${ }^{f}$ Colin M. Dayan ${ }^{a}$ \\ ${ }^{a}$ Thyroid Research Group, Division of Infection and Immunity, Cardiff University, Cardiff, UK; ${ }^{b}$ Wellcome \\ Trust-MRC Institute of Metabolic Science, University of Cambridge, Cambridge, UK; ' ${ }^{\mathrm{D}}$ Department of Endocrinology \\ and Nutrition, La Paz University Hospital, IdiPAZ, Autonomous University of Madrid, Madrid, Spain; ${ }^{\mathrm{d}}$ Department \\ of Endocrinology, University Hospitals Leuven, Leuven, Belgium; ${ }^{e}$ Division of Psychological Medicine and Clinical

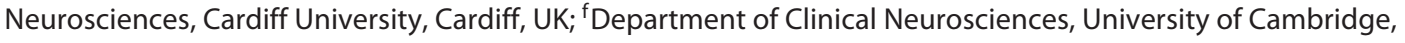 \\ Cambridge, UK
}

\section{Keywords}

Alemtuzumab · Autoimmunity - Autoimmune hypothyroidism - Autoimmune thyroid disease - European thyroid association - Graves' disease - Guidelines · Highly active antiretroviral therapy · Hashimoto's thyroiditis . Hyperthyroidism - Hypothyroidism - Immune reconstitution . Management $\cdot$ Thyroid $\cdot$ Treatment

\footnotetext{
Abstract

Thyroid dysfunction (TD) frequently occurs as an autoimmune complication of immune reconstitution therapy (IRT), especially in individuals with multiple sclerosis treated with alemtuzumab, a pan-lymphocyte depleting drug with subsequent recovery of immune cell numbers. Less frequently, TD is triggered by highly active antiretroviral therapy (HAART) in patients infected with human immunodeficiency virus (HIV), or patients undergoing bone-marrow/hematopoietic-stemcell transplantation (BMT/HSCT). In both alemtuzumab-induced TD and HIV/HAART patients, the commonest disorder is Graves' disease (GD), followed by hypothyroidism and thyroiditis; Graves' orbitopathy is observed in some GD patients. On the contrary, GD is rare post-BMT/HSCT, where hypothyroidism predominates probably as a consequence of the as-
}

sociated radiation damage. In alemtuzumab-induced TD, the autoantibodies against the thyrotropin receptor (TRAb) play a major role, and 2 main aspects distinguish this condition from the spontaneous form: (1) up to $20 \%$ of GD cases exhibit a fluctuating course, with alternating phases of hyperand hypothyroidism, due to the coexistence of TRAb with stimulating and blocking function; (2) TRAb are also positive in about $70 \%$ of hypothyroid patients, with blocking TRAb responsible for nearly half of the cases. The present guidelines will provide up-to-date recommendations and suggestions dedicated to all phases of IRT-induced TD: (1) screening before IRT (recommendations 1-3); (2) monitoring during/ after IRT (recommendations 4-7); (3) management of TD post-IRT (recommendations 8-17). The clinical management of IRT-induced TD, and in particular GD, can be challenging. In these guidelines, we propose a summary algorithm which has particular utility for nonspecialist physicians and which is tailored toward management of alemtuzumab-induced TD. However, we recommend prompt referral to specialist endocrinology services following diagnosis of any IRT-induced TD diagnosis, and in particular for pregnant women and those considering pregnancy.

(C) 2019 The Author(s) Published by S. Karger AG, Basel

\begin{tabular}{ll}
\hline KARGER & $\begin{array}{l}\text { (๑) } 2019 \text { The Author(s) } \\
\text { Published by S. Karger AG, Basel }\end{array}$ \\
E-Mail karger@karger.com & $\begin{array}{l}\text { This article is licensed under the Creative Commons Attribution- } \\
\text { NonCommercial-NoDerivatives 4.0 International License (CC BY- } \\
\text { NC-ND) (http://www.karger.com/Services/OpenAccessLicense). } \\
\text { Www.karger.com/etj }\end{array}$ \\
& Usage and distribution for commercial purposes as well as any dis- \\
tribution of modified material requires written permission.
\end{tabular}

Dr. Ilaria Muller, $\mathrm{MD}, \mathrm{PhD}$

Thyroid Research Group, Division of Infection and Immunity School of Medicine, Cardiff University, University Hospital of Wales, Heath Park Main building Room 256 C2 Link Corridor, Cardiff CF14 4XN (UK) E-Mail ilaria.muller@ hotmail.it 


\section{Introduction}

Thyroid dysfunction (TD) is a common side effect of many treatments acting with different mechanisms, including but not limited to interferon alpha [1], interleukin-2 [2], thalidomide [3], amiodarone [4], radiation therapy [5], lithium [6], bexarotene [7], immune checkpoint inhibitors [8], and thyrosine kinases inhibitors [9, 10]. The present guidelines will focus on thyroid autoimmunity (TA) induced by immune reconstitution therapy (IRT), characterized by a recovery of immune cell numbers following a depletion phase, which to date has been reported in 3 settings: (1) following alemtuzumab (Lemtrada) treatment for active relapsing remitting multiple sclerosis (MS); (2) after treatment of human immunodeficiency virus (HIV) infected patients with highly active antiretroviral therapy (HAART); (3) following allogeneic bone marrow transplantation (BMT) or hematopoietic stem cell transplantation (HSCT) [11]. IRT-induced TA has a late and variable onset, typically occurring 16-23 months after the last alemtuzumab treatment for MS [1214], 8-33 months after the commencement of HAART in HIV patients [15-21], and 2.5-4.3 years post BMT [22].

$\mathrm{T}$ cells are mainly involved in autoimmunity induced by IRT, since this phenomenon has not been described following treatment with B-cell-only depleting agents such as rituximab $[23,24]$. Alemtuzumab is a humanized monoclonal antibody targeting CD52; for the treatment of relapsing remitting MS it is given intravenously as 2 cycles 12 months apart (with additional cycles triggered by clinical or radiological evidence of disease), without additional long-term immunosuppressive drugs. Alemtuzumab causes transient depletion of both B and T lymphocytes (pan-lymphopenia) with an ensuing reconstitution phase characterized by a quick and complete recovery of B lymphocyte numbers (6-12 months) [25], versus a slower and partial recovery of CD4/CD8 T lymphocytes $[26,27]$. Similarly, HIV-infected patients have low CD4 $\mathrm{T}$ cell numbers that increase following HAART [28]. Secondary autoimmunity following allogeneic BMT/HSCT arises by additional mechanisms distinguishing it from the other IRTs including: (1) adoptive immunity, that is transferral of autoreactive lymphocyte clones from the donor to the recipient and (2) graft-versus-host disease with the loss of regulation of autoreactive $\mathrm{T}$ lymphocytes previously kept under control by peripheral immune tolerance $[11,29]$.

TA can also occur as a complication of alemtuzumab treatment administered for other autoimmune disorders, such as vasculitis (11\% prevalence) [30] and Beçhet's dis- ease (25\% prevalence) [31]. However, reliable data to determine incidence and clinical features of TA in these circumstances remain limited. Interestingly, TA has been described only rarely when alemtuzumab is administered for rheumatoid arthritis [32], blood cancers [33], or transplantation [34], suggesting a disease specific and/or genetic background effect. There is a single-case report of Graves' disease (GD) 4 years after alemtuzumab induction for renal transplantation [35]. However, additional possible reasons for this include the use of alternate treatment regimens and frequent combination with the longterm use of other immunosuppressive drugs $[32,33,36]$. It is noteworthy that in the phase 2 trial of alemtuzumab as a treatment of relapsing remitting MS, TD rates were higher in patients treated with a daily dose of $12 \mathrm{mg}$ versus those treated with $24 \mathrm{mg}$ (39 vs. 29\%, Fisher's exact test, $p=0.015$ ) [13]. For the reasons outlined above, these guidelines will therefore predominantly refer to TA induced by alemtuzumab in the context of MS treatment, or HIV/HAART. Note that BMT/HSCT will not be discussed in detail since mainly associated with thyroid disorders, including TA, secondary to the irradiation of the thyroid gland, and are unlikely related to the immune reconstitution alone.

TA caused by IRT is predominantly humoral, inducing a rise of both thyroid-stimulating hormone receptor (TSHR) autoantibodies (TRAb) and autoantibodies to thyroid peroxidase (TPOAb) [13, 17]; in particular, GD is the most common manifestation [14]. Recent studies have demonstrated that TRAb with TSHR-blocking activity (TBAb) are responsible for $30-50 \%$ of all cases of IRT-induced hypothyroidism $[12,37]$, which differs from the spontaneous form of autoimmune hypothyroidism where TBAb account for only $10 \%$ of cases $[38,39]$. The frequency of secondary TA among MS patients treated with alemtuzumab in clinical trials has been reported as between 34 [13] and 41\% [12,14], of which $63[14]-5 \%$ [13] are cases of GD, 21 [13] - 34\% [14] hypothyroidism, and 3 [14] - 12\% [13] subacute/transient thyroiditis.

TA occurring in HIV/HAART patients is less common, with a GD incidence of $3.0 \%$ in women and $0.2 \%$ in men [15], representing a 1.5-2 fold increase compared with the general population [40]. A higher (4-fold) frequency has been noted among black Africans $[15,21]$. The spectrum of TA following HIV/HAART is reported as around $88 \%$ GD, $6 \%$ Hashimoto's thyroiditis, and 6\% hypothyroidism (negative for thyroid autoantibodies) [15].

Following allogeneic BMT/HSCT subclinical or clinical hypothyroidism occurs in $9-30 \%$ of cases, mainly related to radiation to the thyroid gland during the prepar- 
ative regimens [41-43]. Post-BMT/HSCT GD cases are rare and in most cases caused by adoptive immunity [4447].

Online supplementary Table 1 (for all online suppl. material, see www.karger.com/doi/10.1159/000500881) lists the main definitions and abbreviations used.

\section{Methods}

The taskforce for these guidelines was instituted by the executive committee of the European Thyroid Association (ETA). References were searched in PubMed using the following search terms: IRT, secondary TA, alemtuzumab, HIV/HAART, BMT/ HSCT, GD. The Grading of Recommendations Assessment, Development and Evaluation system was used to grade the quality of evidence and the strength of recommendations [48, 49]. It consists of 2 scorings, namely, quality of evidence $(\varnothing 000=$ very low; $\varnothing \varnothing \bigcirc \bigcirc=$ low; $\varnothing \varnothing \varnothing \bigcirc=$ moderate, and $\varnothing \varnothing \varnothing \varnothing=$ high) and strength of recommendation $(1=$ strong, associated with the phrase "we recommend"; 2 = weak, associated with the phrase "we suggest"). The draft guidelines were discussed by the members of the task force and then posted on the ETA website for 4 weeks to receive comments from the ETA members.

A summary of the recommendations is presented in Table 1.

\section{Baseline Thyroid Function Should Be Screened before IRT?}

What Are the Contraindications to IRT?

Around one-third of patients with no previous history of thyroid disorders will develop TD following alemtuzumab [12-14]; therefore, it is important to assess their baseline thyroid function. Small independent studies have suggested that the risk of TD is increased in subjects with established TA [13, 37]. Where thyroidectomy or radioiodine (RAI) ablation has been performed for GD the risk of recurrence would be expected to be low. However, caution is advised in patients with GD in remission after previous medical therapy, and also those with previous lymphocytic (autoimmune) or post-partum thyroiditis. In patients on thyroid hormone replacement for hypothyroidism, caution is also advised as fluctuation in the autoimmune state and thyroid status is possible; there is currently no evidence to quantify this risk.

\section{Recommendations}

1a. We recommend the measurement of thyroid-stimulating hormone (TSH) in all subjects before IRT. Free-thyroxine (FT4), and free-triiodothyronine (FT3) if available, should be measured where TSH is abnormal $(1, \varnothing \varnothing \bigcirc \bigcirc)$.

1b. Baseline or previous TD is not a contraindication to initiation or repeated treatment with IRT. In cases of previous/baseline GD in remission or autoimmune hypothyroidism or post-partum thyroiditis, we recommend close monitoring by an endocrinologist with investigation and treatment (if necessary) before IRT ( 1 , $\varnothing \varnothing \bigcirc \bigcirc)$.

1c. Active thyroid eye disease and cardiac disease where thyrotoxicosis would be a significant risk should be considered contraindications to IRT; we recommend controlling/treating these conditions before IRT $(1, \varnothing \bigcirc \bigcirc)$ ).

ETA Guidelines on Thyroid Dysfunction

following Immune Reconstitution
2. Should Thyroid Autoantibodies (TPOAb and TRAb) Be

Tested before IRT?

In one study, $69 \%$ of MS patients who had positive TPOAb before receiving alemtuzumab developed TD, compared to $31 \%$ of those with negative TPOAb. However, the number of patients with baseline positive TPOAb levels was small $(n=16)$, and $85 \%$ of those developing TD were TPOAb negative at baseline [13]. Hence, while pretreatment TPOAb levels may help to identify patients at particular risk of post-alemtuzumab TD, a surveillance program directed at only these individuals would not detect the majority of TD.

Similarly, TRAb measured with published specialized in-house assays, but not standard clinical automated assays, have been detected at baseline in about one-third of patients that will later develop TD, with a similar predictive role to TPOAb [37]. No data support the routine TRAb measurement using standard commercial assays before commencement of alemtuzumab; where checked it was almost uniformly negative, and if positive, patients often did not receive the study drug $[13,50]$.

The value of baseline antithyroid antibody levels before alemtuzumab treatment for indications other than MS has not been studied [30].

\section{Recommendation}

2. We do not suggest routine measurement of TPOAb or TRAb before IRT, although the TD risk is increased in thyroid-autoantibody positive patients $(2, \varnothing \varnothing \bigcirc \bigcirc)$.

\section{Should Thyroid Imaging Be Performed before IRT?}

Thyroid scintigraphy is only indicated before IRT in case of low TSH levels associated with negative TRAb and/or nodularity [5153].

Recommendation

3. We do not recommend routine thyroid ultrasound or scintigraphy scans before IRT $(1, \varnothing \varnothing \varnothing \bigcirc)$.

\section{Which Thyroid Function Test(s) Should Be Used to Assess}

Thyroid Status after IRT?

The commonest TD occurring post-alemtuzumab and in HIV/ HAART patients is GD, followed by hypothyroidism and thyroiditis $[12,13,15]$. GD is rare post-BMT/HSCT [44-47], where hypothyroidism predominates [41-43]. In all of these conditions, a change in TSH levels is the earliest abnormality identified on thyroid function testing.

\section{Recommendations}

4a. We recommend TSH testing to assess for post-IRT TD. Depending on local resources, FT4 may be also routinely measured $(1, \varnothing \varnothing \varnothing \bigcirc)$.

4b. We recommend repeat TSH testing within 1 month if the TSH level is low $(0.10-0.39 \mathrm{mU} / \mathrm{L} ; 1, \varnothing \varnothing \bigcirc \bigcirc)$.

$4 c$. We recommend repeat TSH testing within 2 weeks together with FT4 if TSH is elevated, and with FT4 and FT3 if TSH is suppressed $(<0.10 \mathrm{mU} / \mathrm{L})$. A full history and examination should also be performed, focusing on thyroid signs, symptoms, and contributing factors $(1, \varnothing \varnothing \varnothing \bigcirc)$. 
Table 1. Recommendations

Recommendation

Comments

Strength/leve

of evidence

Recommendations before IRT (recommendations 1-3)

1. Baseline thyroid function should be screened before IRT? What are the contraindications to IRT? 1a. We recommend TSH measurement in all subjects before IRT; FT4 (FT3 if available) should be measured where TSH is abnormal

1b. Baseline or previous TD is not a contraindication to initiation or repeated treatment with IRT; in cases of previous/baseline GD in remission or autoimmune hypothyroidism or post-partum thyroiditis, we recommend close monitoring by an endocrinologist with investigation and treatment (if necessary) before IRT 1c. Active thyroid eye disease and cardiac disease where thyrotoxicosis would be a significant risk are contra-indications to IRT; we recommend controlling/treating these conditions before IRT

2. Should thyroid autoantibodies (TPOAb and TRAb) be tested before IRT?

2. We do not suggest routine measurement of TPOAb or TRAb before IRT, although

$2, \varnothing \varnothing \bigcirc \bigcirc$ the TD risk is increased in thyroid-autoantibody positive patients

3. Should thyroid imaging be performed

3. We do not recommend routine thyroid ultrasound or scintigraphy scans before IRT
$1, \varnothing \varnothing \varnothing 0$

$1, \varnothing \varnothing \bigcirc \bigcirc$

$1, \varnothing \varnothing \bigcirc \bigcirc$

$1, \varnothing \bigcirc \bigcirc \bigcirc$

Monitoring of patients receiving IRT (recommendations 4-7)

4. Which thyroid function test(s) should be used to assess thyroid status after IRT? 4a. We recommend TSH testing to assess for post-IRT TD; depending on local resources, FT4 may be also routinely measured $4 \mathrm{~b}$. We recommend repeat TSH testing within 1 month if the TSH level is low $(0.10$ $0.39 \mathrm{mU} / \mathrm{L})$

4c. We recommend repeat TSH testing within 2 weeks together with FT4 if TSH is elevated, and with FT4 and FT3 if TSH is suppressed $(<0.10 \mathrm{mU} / \mathrm{L})$; a full history and examination should also be performed, focusing on thyroid signs, symptoms, and contributing factors

5. How frequently should thyroid function be tested after IRT?

5a. Following alemtuzumab, we recommend instituting biochemical follow-up with TSH testing every 3 months (Fig. 1); time points should not be missed, as TD can develop rapidly; therefore, efforts should be made to ensure patients do not miss appointments

$5 \mathrm{~b}$. We recommend advising IRT patients to alert the medical team if they develop signs and symptoms of TD, that is, excessive sweating, unexplained weight loss or gain, nervousness, tachycardia, and worsening tiredness

$5 \mathrm{c}$. We do not recommend routine TSH monitoring following HAART in HIV patients

TSH measurement should be performed if TD is suspected on clinical grounds

$5 \mathrm{~d}$. We suggest to manage the long-term follow-up of patients after BMT/HSCT within a dedicated specialized setting

6. For how long post-IRT routine thyroid function testing should be performed?

6 a. We recommend routine 3 monthly measuring of thyroid function to be continued for 4 years from the last alemtuzumab treatment (Fig. 1)

6b. After this period, testing should be performed based on symptoms and signs suggestive of TD

7. We do not recommend routine measurement of thyroid autoantibodies in euthyroid patients during surveillance

7. Should thyroid autoantibodies be measured in euthyroid individuals during
$1, \varnothing \varnothing \varnothing \bigcirc$

$1, \varnothing \varnothing \bigcirc \bigcirc$

$1, \varnothing \varnothing \varnothing \bigcirc$

$1, \varnothing \varnothing \bigcirc \bigcirc$

$1, \varnothing \varnothing \bigcirc \bigcirc$

$2, \varnothing \bigcirc \bigcirc \bigcirc$

$1, \varnothing \varnothing \bigcirc \bigcirc$

$1, \varnothing \varnothing \bigcirc \bigcirc$

$1, \varnothing \bigcirc \bigcirc \bigcirc$ routine monitoring for TD following IRT?

Management and referral of patients who develop post-IRT TD (recommendations 8-17)

8. Should patients be routinely screened

8. We do not recommend routine thyroid ultrasound or scintigraphy post IRT

$1, \varnothing \varnothing \varnothing 0$ with thyroid imaging post IRT?

9. When should patients with post-IRT TD

9a. We recommend referral to and review by an endocrinologist within 2-4 weeks in

$1, \varnothing \bigcirc \bigcirc \bigcirc$

be referred to an endocrinologist?

case of abnormal thyroid function confirmed on repeat testing, including asymptomatic cases

$9 \mathrm{~b}$. Depending on the local organization of clinical services, we suggest the use of a clinical thyroid management algorithm developed for nonspecialist physicians and based on alemtuzumab-induced TD (Fig. 2); however, this should be combined with the availability of an endocrinologist in case of urgent thyroid-related problems or a complicated disease course 
Table 1 (continued)

Recommendation

Comments

10. What are the recommendations for pregnant patients or patients planning pregnancy? 10a. We suggest that the thyroid function of women pregnant or seeking pregnancy within 4 years of last IRT should be monitored more frequently (i.e., monthly) 10b. According to local resources and services, we suggest that these women should be immediately referred to an endocrinologist as soon as they develop TD, to be commenced on appropriate thyroid treatment and monitoring during pregnancy in a specialist setting
11. What investigation should be performed in patients found to have post-IRT biochemical thyrotoxicosis?

12. When should the treatment for abnormal thyroid function be commenced?
11. If biochemistry is consistent with thyrotoxicosis post-IRT, we recommend the measurement of TRAb and/or radionuclide scintigraphy to distinguish between GD and destructive thyroiditis (Fig. 2A); ultrasonography with color-flow or power Doppler examination can also be considered
Strength/leve of evidence

$2, \varnothing 000$

2, Ø०००

$1, \varnothing \varnothing \varnothing \bigcirc$

$12 \mathrm{a}$. We recommend to promptly initiate treatment if the patient is symptomatic or at high risk (pregnancy, cardiovascular disease), or if TD persists $>3$ months $12 \mathrm{~b}$. In the other cases, we suggest to delay treatment by 3 months to determine if the TD spontaneously resolves, or the thyroid function fluctuates

13. What is the management of post-IRT GD? (Fig. 2a)

13a. We recommend treating patients with persistent hyperthyroidism and/or symptomatic GD with for 12-18 consecutive months as first-line treatment 13b. We suggest consideration of a block and replace regimen (high-dose ATD with replacement LT4) for a better control of GD with fluctuating thyroid status (variability in thyroid status unexplained by changes in ATD)

13c. We suggest consideration of RAI and surgery for hyperthyroid GD in cases of relapsing disease, drug intolerability, patient preference, or uncontrolled fluctuating disease course (variability in thyroid status unexplained by changes in ATD)

14. How should post-IRT hypothyroidism be further investigated?

14. We recommend measurement of both TPOAb and TRAb antibodies in patients who develop hypothyroidism following IRT, using TRAb assays not influenced by high TSH levels
15. How should post-IRT hypothyroidism be managed? (Fig. 2b)

15a. We recommend commencing LT4 in patients with overt hypothyroidism

$15 \mathrm{~b}$. We recommend commencing LT4 in cases of mild (subclinical) and persistent ( $>3$ months) hypothyroidism with symptoms

15c. We recommend monitoring TSH and FT4 every 3 months for the first year after thyroxine initiation in cases of negative TRAb, then as per local hypothyroidism guidelines

$15 \mathrm{~d}$. We suggest monitoring TSH and FT4 every month during 6 months after LT4 initiation in cases of positive TRAb, then every 3 months; if stable, can be monitored as per local hypothyroidism guidelines

15e. We suggest to manage hypothyroidism with positive TRAb in a specialist setting, or refer to an endocrinologist if thyrotoxicosis develop

15f. We suggest a trial off LT4 after 12 months to determine if hypothyroidism post-

IRT has resolved, especially in hypothyroid cases with positive TRAb, hypothyroidism preceded by thyrotoxicosis or a daily LT4 dose $\leq 50 \mu \mathrm{g}$

$15 \mathrm{~g}$. We recommend to continue LT4 and keep TSH in the normal range as per ETA [83] and ATA [84] guidelines in case of women with post-IRT hypothyroidism seeking pregnancy, postponing the trial off LT4 until after delivery and breastfeeding

16. How should post-IRT thyroiditis be managed?

16. We recommend a conservative approach with only symptomatic support (beta blockade) of subjects with confirmed thyroiditis (see recommendation 11), but close follow-up as other forms of TD may develop; treatment with steroids could be considered in cases of severe neck pain or severe thyrotoxicosis

17. How should post-IRT GO be managed? 17a. We recommend advising IRT patients to alert the medical team if they develop signs and symptoms of GO, such as proptosis, diplopia, orbital inflammation $17 \mathrm{~b}$. We suggest managing GO post-IRT in the same way as spontaneous disease [90]; in MS patients a careful drug history is required, since they might be already on steroid treatment
$1, \varnothing \varnothing \bigcirc \bigcirc$

2, Ø०००

$1, \varnothing \varnothing \varnothing \bigcirc$

2, Ø०००

2, Ø०००

$1, \varnothing \varnothing \bigcirc \bigcirc$

$1, \varnothing 000$

$1, \varnothing \bigcirc 0 \bigcirc$

$2, \varnothing \bigcirc 00$

2, Ø०००

2, Ø๐००

$1, \varnothing \varnothing \varnothing 0$

$1, \varnothing 000$

$1, \varnothing \varnothing \bigcirc \bigcirc$

$2, \varnothing 000$

IRT, immune reconstitution therapy; TSH, thyroid-stimulating hormone; FT4, free-thyroxine; FT3, free-triiodothyronine; TD, thyroid dysfunction; GD, Graves' disease; TPOAb, autoantibodies to thyroid peroxidase; TRAb, thyrotropin autoantibodies; HAART, highly active antiretroviral therapy; HIV, human immunodeficiency virus; BMT/HSCT, bone-marrow/hematopoietic-stem-cell transplantation; ATD, antithyroid drug; LT4, levothyroxine; GO, Graves' orbitopathy.

ETA Guidelines on Thyroid Dysfunction following Immune Reconstitution 


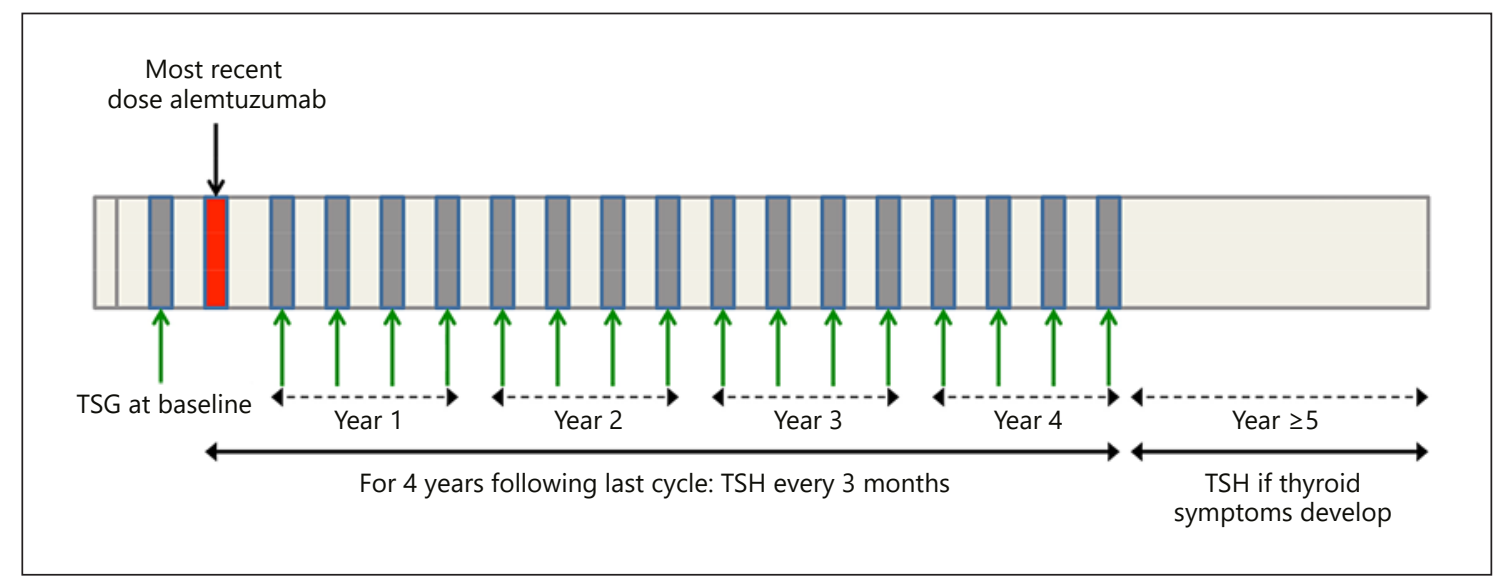

Fig. 1. Following alemtuzumab, we recommend instituting biochemical follow-up with TSH testing every 3 months. Moreover, we recommend routine 3 monthly measuring of thyroid function to be continued for 4 years from the LAST alemtuzumab treatment. TSH, thyroid-stimulating hormone.

\section{How Frequently Should Thyroid Function Be Tested after} IRT?

Considering the high incidence of TD, the European Public Assessment Report of the European Medicines Agency about Lemtrada's use in MS patients recommends testing thyroid function every 3 months for 4 years after the last alemtuzumab dose [54].

TD following HAART is less common and relates mostly to GD [15]. A cross-sectional study reported a higher TD prevalence (34\%) among HIV-infected adults; however, it could be partially attributed to non-thyroidal or pituitary disease $(13 \%$ had low FT4, either isolated or with low TSH; $1 \%$ had isolated raised FT4); the majority of the remainder had overt or subclinical hypothyroidism [55]. The Infectious Diseases Society of America does not recommend regular thyroid function testing in HIV patients [56].

There is no universal agreement on timing of thyroid function monitoring after allogeneic BMT/HSCT, ranging from 3-6 months [22] to 1 year [42], and current lack of standardized guidelines for long-term follow-up of BMT/HSCT survivors, also susceptible to many additional compliances other than TD [42].

\section{Recommendations}

5a. Following alemtuzumab, we recommend instituting biochemical follow-up with TSH testing every 3 months (Fig. 1). Time points should not be missed, as TD can develop rapidly; therefore, efforts should be made to ensure patients do not miss appointments $(1, \varnothing \varnothing \bigcirc \bigcirc)$.

$5 \mathrm{~b}$. We recommend advising IRT patients to alert the medical team if they develop signs and symptoms of TD, such as, excessive sweating, unexplained weight loss or gain, nervousness, tachycardia, and worsening tiredness $(1, \varnothing \varnothing \bigcirc \bigcirc)$.

$5 \mathrm{c}$. We do not recommend routine TSH monitoring following HAART in HIV patients; TSH measurement should be performed if TD is suspected on clinical grounds $(1, \varnothing \varnothing \bigcirc \bigcirc)$.

$5 \mathrm{~d}$. We suggest to manage the long-term follow-up of patients after BMT/HSCT within a dedicated specialized setting (2, $\varnothing \bigcirc \bigcirc \bigcirc)$.

\section{For How Long post-IRT Routine Thyroid Function Testing Should Be Performed?}

The TD onset has been described 32 months (average) or 16-23 months (range 2-107 months) after the first and last alemtuzumab treatment for MS, respectively [12-14], with frequent episodes of transient autoimmune thyroiditis reported 6-12 months before GD onset (panel member's personal experience). In the extension studies of alemtuzumab for MS (5 years follow-up), TD peaked at year 3 , declining thereafter $[57,58]$. However, late cases (rarely) of TD have been reported up to 9 years after the last alemtuzumab dose [12]. The European Medicines Agency's Lemtrada-European Public Assessment Report recommends testing thyroid function every 3 months for 4 years after the last alemtuzumab dose [54].

Among HIV patients GD occurred 8-33 months (mean 17 months) after HAART initiation [15-21].

Recommendations

6a. We recommend routine 3 monthly measuring of thyroid function to be continued for 4 years from the LAST alemtuzumab

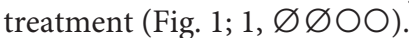

6b. After this period, testing should be performed based on symptoms and signs suggestive of TD $(1, \varnothing \varnothing \bigcirc \bigcirc)$.

\section{Should Thyroid Autoantibodies Be Measured in Euthyroid}

Individuals during Routine Monitoring for TD following IRT?

Although TRAb and TPOAb became positive during postalemtuzumab surveillance, not all of these patients developed TD, so the significance of positive antibodies in such asymptomatic, euthyroid individuals is unclear [13]. Similarly, a number of patients developed TD but remained antibody negative [12, 13]. Hence, at present, there is insufficient evidence to determine whether knowledge of antibody status during surveillance would inform or alter the frequency of thyroid function testing in alemtuzumab-treated patients.

TRAb and TPOAb became positive only 3-4 months (median) before the TD onset following HAART in a small patient cohort [17]; therefore, the detection of preclinical disease would not alter the monitoring or management of TD. 
Recommendation

7. We do not recommend routine measurement of thyroid autoantibodies in euthyroid patients during surveillance $(1, \varnothing \bigcirc \bigcirc \bigcirc)$.

8. Should Patients Be Routinely Screened with Thyroid Imaging post IRT?

In the phase III clinical trials comparing alemtuzumab with interferon $\beta$-1a in highly active MS, no overall increase in malignancy was observed; however, papillary thyroid cancer was discovered in $0.4 \%$ of alemtuzumab-treated patients $[59,60]$. Such frequency may have been influenced by ascertainment bias during the alemtuzumab clinical development program $[61,62]$. In the 5-year follow-up extension studies, no increase in thyroid cancer was observed $[57,58]$.

Before HAART, HIV patients due to immunodeficiency are at increased risk for opportunistic infectious thyroid disease (subacute thyroiditis or rarely suppurative thyroiditis) that usually is part of a disseminated infection (e.g., by mycobacterium tuberculosis/avium, CMV, cryptococcus, pneumocystis) [63]. Infectious thyroiditis rarely causes a clinical TD, but when this occurs thyroid ultrasound and fine-needle aspiration cytology are indicated. HIV patients are also at increased risk for malignancy with potential localization in the thyroid, especially Kaposi sarcoma and lymphoma $[64,65]$. In the post-HAART era, a decrease is observed in AIDS-associated cancers, but an increase is seen in other cancer types such as lung cancer and cervix carcinoma [66, 67].

Overall, there is no evidence for an increased risk of thyroid malignancy after IRT. Due to the high prevalence of thyroid nodules in the population and the very low risk of thyroid cancer, routine thyroid US in the context of IRT is not indicated and carries the risk of overdiagnosis and subsequent overtreatment [68]. This does not to apply to cases where radiation therapy is also administered (i.e., BMT/HSCT) and is not the object of the present guidelines.

\section{Recommendation}

8. We do not recommend routine thyroid ultrasound or scintigraphy post IRT $(1, \varnothing \varnothing \varnothing \bigcirc)$.

\section{When Should Patients with post-IRT TD Be Referred to an} Endocrinologist?

Post-IRT TD might follow an atypical fluctuating course, necessitating appropriate diagnostic and therapeutic management [69]. Clinical symptoms can take up to 3 months to develop following biochemical TD. As a result, routine monitoring of thyroid function may mean that biochemical abnormalities are detected in the absence of clinical symptoms.

Among all cases of post-IRT TD, those triggered by alemtuzumab are the most common and better evaluated, therefore allowing to design algorithms for its clinical management, as previously published in 2018 [70]. Here we provide an updated version of such algorithm (Fig. 2), including the importance of TRAb measurement in hypothyroid cases and alerting clinicians about the possibility of fluctuating disease course in GD.

\section{Recommendations}

9 a. We recommend referral to and review by an endocrinologist within 2-4 weeks in case of abnormal thyroid function confirmed on repeat testing, including asymptomatic cases (1, $\varnothing \bigcirc \bigcirc \bigcirc)$

ETA Guidelines on Thyroid Dysfunction

following Immune Reconstitution 9b. Depending on the local organization of clinical services, we suggest the use of a clinical thyroid management algorithm developed for nonspecialist physicians and based on alemtuzumab-induced TD (Fig. 2). However, this should be combined with the availability of an endocrinologist in case of urgent thyroid-related problems or a complicated disease course $(2, \varnothing \bigcirc \bigcirc \bigcirc)$.

\section{What Are the Recommendations for Pregnant Patients or}

Patients Planning Pregnancy?

The maternal gestational thyroid function has a crucial impact on pregnancy, fetal, and neonatal outcomes; therefore, TD occurring during pregnancy, especially if overt, require a prompt correction $[71,72]$.

\section{Recommendations}

10a. We suggest that the thyroid function of women pregnant or seeking pregnancy within 4 years of last IRT should be monitored more frequently (i.e., monthly; $2, \varnothing \bigcirc \bigcirc \bigcirc)$ ).

10b. According to local resources and services, we suggest that these women should be immediately referred to an endocrinologist as soon as they develop TD, to be commenced on appropriate thyroid treatment and monitoring during pregnancy in a specialist setting $(2, \varnothing \bigcirc \bigcirc \bigcirc)$.

11. What Investigation Should Be Performed in Patients Found to Have post-IRT Biochemical Thyrotoxicosis?

The possible causes of post-IRT thyrotoxicosis are GD or destructive thyroiditis; other causes are unlikely in individuals who had persistently normal thyroid function before IRT $[12,13]$.

It is important to distinguish between these etiologies, since treatment will differ. Around $85-100 \%$ of patients with alemtuzumab-induced GD have positive TRAb $[12,13]$. In cases where TRAb is negative or not available, thyroid scintigraphy will distinguish between GD (diffusely increased uptake) and destructive thyroiditis (reduced uptake) [73]; however, radionuclide uptake is not routinely reported in IRT literature $[12,13]$. Ultrasonography with color-flow or power Doppler examination can also be considered to assess the intrathyroidal vascularity and the superior thyroid artery peak systolic velocity, usually both increased in GD [74-76].

\section{Recommendation (Fig. 2a)}

11. If biochemistry is consistent with thyrotoxicosis post-IRT, we recommend the measurement of TRAb and/or radionuclide scintigraphy to distinguish between GD and destructive thyroiditis. Ultrasonography with color-flow or power Doppler examination can also be considered $(1, \varnothing \varnothing \varnothing \bigcirc)$.

\section{When Should the Treatment for Abnormal Thyroid}

Function Be Commenced?

Around $20 \%$ of patients with confirmed TD post-alemtuzumab have a fluctuating course or only transient dysfunction $(<3-6$ months) $[12,13,37]$. Hence, close monitoring (monthly thyroid function) before commencing treatment is advised.

\section{Recommendations}

12a. We recommend to promptly initiate treatment if the patient is symptomatic or at high risk (pregnancy, cardiovascular disease), or if TD persists $>3$ months $(1, \varnothing \varnothing \bigcirc \bigcirc)$. 


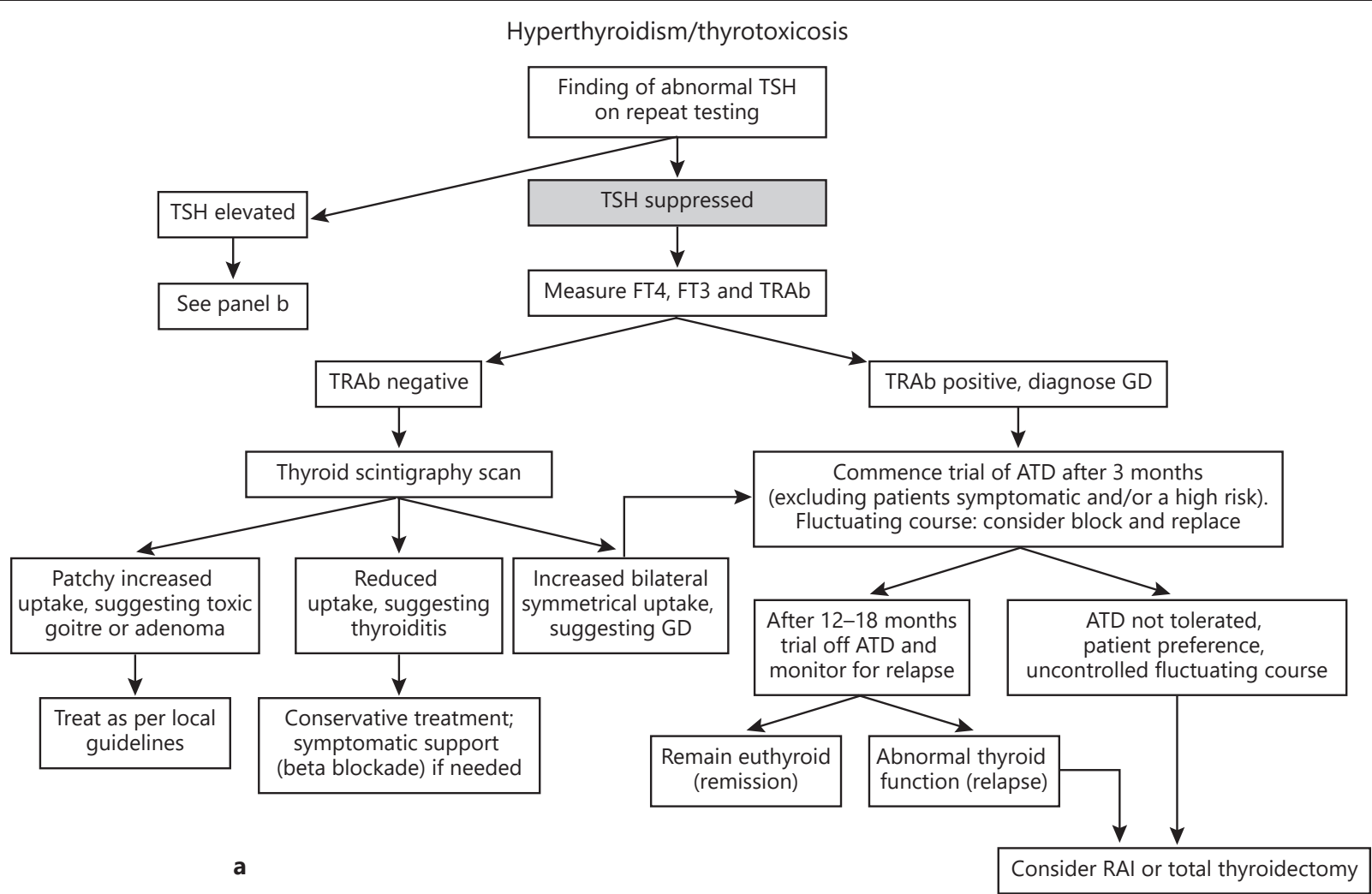

Hypothyroidism

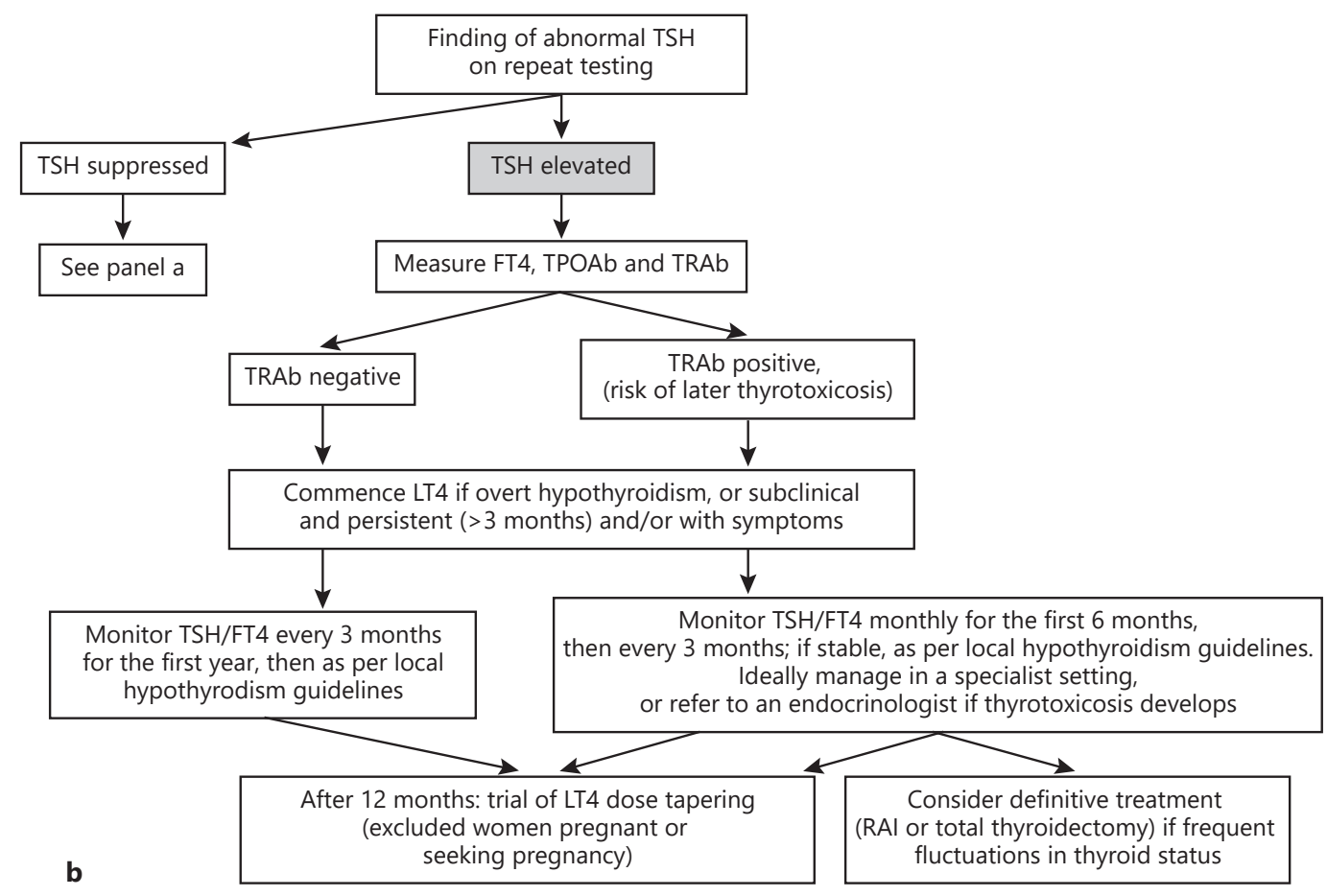

Fig. 2. a Hyperthyroidism/thyrotoxicosis. b Hypothyroidism. TSH, thyroid-stimulating hormone; TRAb, thyrotropin receptor autoantibodies; FT4, free-thyroxine; FT3, free-triiodothyronine; GD, Graves' disease; ATD, antithyroid drug; RAI, radioiodine; TPOAb, autoantibodies to thyroid peroxidase; LT4, levothyroxine. 
$12 \mathrm{~b}$. In the other cases, we suggest to delay treatment by 3 months to determine if the TD spontaneously resolves, or the thyroid function fluctuates $(2, \varnothing \bigcirc \bigcirc \bigcirc)$.

\section{What Is the Management of post-IRT GD?}

Few studies have reported the type of treatment used and response to therapy in alemtuzumab-induced GD. In the studies that have, most patients responded to antithyroid drugs (ATDs) [12$14,50,77]$, at least initially.

Approximately one-third of patients with subclinical hyperthyroidism due to spontaneous GD undergo spontaneous resolution [78]; similarly, some studies have reported spontaneous resolution of post-IRT GD in $20 \%$ of cases [13], while others did not [12, 77]. This difference may be related to differences in the definition of TD: persistent for $\geq 3$ months in Pariani et al. [12] versus present on one occasion in Daniels et al. [13]. In addition, subclinical disease is described as a frequent occurrence in one series; subclinical hypothyroidism constituted $23 \%$ of hypothyroidism, with 1 of 7 patients requiring levothyroxine (LT4) treatment; 19\% of GD was subclinical with 4 out of 11 requiring ATD [13]. Other studies either did not distinguish between subclinical and clinical disease or did not observe it [12]. Of note, a patient subset (30\%) experienced numerous TD episodes post-alemtuzumab [13]; of these, $86 \%(19 / 22)$ had GD; 2 of the remainder had positive TRAb. Another study showed that $19 \%$ of GD patients displayed a fluctuating disease course, with sudden and unexpected changes from thyrotoxicosis to hypothyroidism and vice versa [79]: the presence of both blocking and stimulating TRAb was demonstrated in a subset of these [12].

The literature is contradictory in terms of the relapse rates and requirements for definitive treatment in alemtuzumab-induced GD, with the lowest long-term remission rate being 34\% [12]. In 1999, Coles et al. [50] reported 7/9 (78\%) patients relapsed after a course of block and replace therapy; 4 had subsequent RAI treatment, 1 thyroidectomy, and 2 a second course of ATD. Pariani et al. [12] reported a high requirement (64\%) for long-term ATD, RAI or surgery, compared with approximately $50 \%$ in conventional GD [80]. In contrast, requirements for RAI or surgery were lower than expected in conventional GD in some reports; $14 \%$ [14], 27\% [77]. Given the uncertainty regarding response to treatment, it is reasonable to use definitive treatments for IRTinduced GD in situations similar to that of conventional GD; cases with fluctuating thyroid function may require a different approach.

The majority of post-HAART GD responds to ATD [20, 21], with a small number of patients requiring definitive treatment. Long-term relapse rates are not reported.

Recommendations (Fig. 2a)

13a. We recommend treating patients with persistent hyperthyroidism and/or symptomatic GD with ATD for 12-18 consecutive months as first-line treatment $(1, \varnothing \varnothing \varnothing \bigcirc)$.

$13 \mathrm{~b}$. We suggest consideration of a block and replace regimen (high-dose ATD with replacement LT4) for a better control of GD with fluctuating thyroid status (variability in thyroid status unexplained by changes in ATD; $2, \varnothing \bigcirc \bigcirc \bigcirc)$.

13c. We suggest consideration of RAI and surgery for hyperthyroid GD in cases of relapsing disease, drug intolerability, patient preference, or uncontrolled fluctuating disease course (variability in thyroid status unexplained by changes in ATD; 2, $\varnothing \bigcirc \bigcirc \bigcirc)$.

ETA Guidelines on Thyroid Dysfunction following Immune Reconstitution

\section{How Should post-IRT Hypothyroidism Be Further} Investigated?

Development of subclinical (normal FT4), or overt (low FT4) hypothyroidism, is heralded by increased TSH levels. Hypothyroidism accounts for approximately $20-34 \%$ of post-alemtuzumab TD and is associated with positivity of thyroid autoantibodies in the majority of cases (TPOAb alone in $1 / 3$, TRAb and/or TPOAb in $2 / 3)[12,13]$.

TRAb with blocking activity on TSHR (TBAb) are responsible for around $30-50 \%$ of all hypothyroid cases [37]. Patients who initially present with hypothyroidism and positive TRAb can later develop thyrotoxicosis requiring ATD; these patients can exhibit fluctuating GD with unexpected changes from hypo- to hyperthyroidism and vice versa (19\% of cases) [12]. Hence, TRAb measurement in hypothyroid patients can identify those in whom a more intensive biochemical surveillance strategy is advised.

When measuring TRAb levels in hypothyroid patients, it is important to exclude false-positive cases due to high TSH levels. Some of the most widely used commercial kits (Brahms Lumitest, Brahms RIA, Roche Elecsys, RSR-Coated tube RIA, RSR 3rd Gen ELISA, Siemens Immulite) did not show any cross reactivity with high levels of TSH (i.e., >140 mU/L), as reported in their technical information sheets.

The phenomenon of fluctuating GD or TRAb-positive hypothyroidism has not been reported following HAART, but has been seen following alemtuzumab administration for vasculitis (panel member's personal experience).

\section{Recommendation}

14. We recommend measurement of both TPOAb and TRAb antibodies in patients who develop hypothyroidism following IRT,

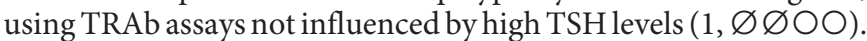

\section{How Should post-IRT Hypothyroidism Be Managed?}

When overt or clinical hypothyroidism develops, treatment with LT4 is indicated according to the general guidelines [81].

In contrast to the usually irreversible hypothyroidism of classical Hashimoto's thyroiditis disease, a higher frequency of potential reversibility needs to be considered in hypothyroidism developing post-IRT, as a higher frequency of atypical autoimmune thyroid disease is reported [69]. This finding is likely related to TRAb found positive in about $70 \%$ of hypothyroid cases $[12,13]$ and with described blocking activity (TBAb) [37]. TRAb measurement should be considered in cases of post-IRT hypothyroidism; TRAb presence indicates potential later recovery from hypothyroidism since TBAb usually do not persist for a long time [79].

In HIV patients, usually hypothyroidism is not associated with $\mathrm{TPOAb} / \mathrm{TRAb}$ positivity, suggesting a non-autoimmune pathophysiology, that is, infectious thyroiditis [82].

Recommendations (Fig. 2b)

15a. We recommend commencing LT4 in patients with overt hypothyroidism $(1, \varnothing \varnothing \varnothing \bigcirc)$.

$15 \mathrm{~b}$. We recommend commencing LT4 in cases of mild (subclinical) and persistent ( $>3$ months) hypothyroidism with symptoms $(1, \varnothing \bigcirc \bigcirc \bigcirc)$.

$15 \mathrm{c}$. We recommend monitoring TSH and FT4 every 3 months for the first year after LT4 initiation in cases of negative TRAb, then as per local hypothyroidism guidelines $(1, \varnothing \bigcirc \bigcirc \bigcirc)$. 
$15 \mathrm{~d}$. We suggest monitoring TSH and FT4 every month during 6 months after LT4 initiation in cases of positive TRAb, then every 3 months. If stable, they can be monitored as per local hypothyroidism guidelines $(2, \varnothing \bigcirc \bigcirc \bigcirc)$.

$15 \mathrm{e}$. We suggest to manage hypothyroidism with positive TRAb in a specialist setting or refer to an endocrinologist if thyrotoxicosis develop $(2, \varnothing \bigcirc \bigcirc \bigcirc)$.

$15 f$. We suggest a trial off LT4 after 12 months to determine if hypothyroidism post-IRT has resolved, especially in hypothyroid cases with positive TRAb, hypothyroidism preceded by thyrotoxicosis or a daily LT4 dose $\leq 50 \mu \mathrm{g}(2, \varnothing \bigcirc \bigcirc \bigcirc)$.

$15 \mathrm{~g}$. We recommend to continue LT4 and keep TSH in the normal range as per ETA [83] and ATA [84] guidelines in case of women with post-IRT hypothyroidism seeking pregnancy, postponing the trial off LT4 until after delivery and breastfeeding (1, $\varnothing \varnothing \varnothing \bigcirc)$.

\section{How Should post-IRT Thyroiditis Be Managed?}

Cases with a fluctuating TD course and negative TRAb were assumed to be thyroiditis - accounting for $5-10 \%$ of patients with post-alemtuzumab TD $[12,13]$. In the series from Daniels et al. [13], one case developed GD after painless thyroiditis; another case developed hypothyroidism post-thyroiditis followed by another episode of painless thyroiditis.

No precise data about the prevalence of thyroiditis secondary to different IRT forms are available; hence, it is difficult to be certain of the etiology.

\section{Recommendation}

16. We recommend a conservative approach with only symptomatic support (beta blockade) of subjects with confirmed thyroiditis (see recommendation 11), but close follow-up as other forms of TD may develop. Treatment with steroids could be considered in cases of severe neck pain or severe thyrotoxicosis (1, $\varnothing \bigcirc \bigcirc \bigcirc)$.

\section{How Should post-IRT Graves' Orbitopathy Be Managed?}

In spontaneous GD, some degree of ocular involvement has been reported in about $30-50 \%$ of cases $[85,86]$. In particular, mild-inactive and moderate-to-very-severe Graves' orbitopathy (GO) is present in about $20 \%$ and $5-6 \%$ of GD patients, respectively $[87,88]$. Less data are available regarding the GO prevalence among patients with post-IRT GD. A recent study described a $13 \%$ GO prevalence among 52 post-alemtuzumab GD patients, particularly severe in 2 cases (both non-smokers), and possibly linked to RAI treatment without steroid cover in one individual [12].

A GO-focused cross-sectional study identified 3/11 (27\%) patients with HIV/HAART-induced GD developing GO, characterized by different EUGOGO severity: 1 mild, 1 moderate-severe, 1 sight threatening [89]. There is no evidence suggesting that the clinical management of GO in post-IRT GD should be different from the spontaneous form [90]. The clinical management of GO in HIV patients involves additional challenges, since HAART conflicts with ATD, immunosuppressive treatments and analgesics for orbital decompression surgery often used in GO treatment [89].

\section{Recommendations}

17a. We recommend advising IRT patients to alert the medical team if they develop signs and symptoms of GO, such as proptosis, diplopia, orbital inflammation $(1, \varnothing \varnothing \bigcirc \bigcirc)$. 17b. We suggest managing GO post-IRT in the same way as spontaneous disease [90]. In MS patients, a careful drug history is required, since they might be already on steroid treatment (2, $\varnothing \bigcirc \bigcirc \bigcirc)$

\section{Discussion and Future Developments}

The present guidelines provide recommendations and suggestions for the clinical management of TD of autoimmune etiology triggered by IRT. The commonest cause is alemtuzumab treatment of individuals with active relapsing remitting MS, followed by HAART treatment in HIV patients. For this reason, we have tailored our clinical algorithm toward alemtuzumab-induced thyroid disorders, highlighting the differences with the spontaneous form and guiding the clinician through key examinations for correct diagnosis and appropriate clinical management. Less commonly, TD occurs after BMT/HSCT; however, as different mechanisms of radiation-induced thyroid damage are also involved in the development of $\mathrm{TD}$, it does not represent a central topic for these guidelines.

The prevalence of TD post-alemtuzumab is likely to increase in the near future since alemtuzumab was only licensed for MS in 2013, and thyroid complications are a delayed adverse effect of treatment. However, efforts are being made to mitigate the autoimmunity induced by alemtuzumab, and a wider spectrum of effective treatments for MS are being developed (including but not limited to ocrelizumab, cladribine, opicinumab), which appear not to be associated with autoimmunity (although have their own set of side effects) [91-93]. Hence, in the longer term, rates of TD associated with alemtuzumab may fall. Similarly, during the past 20 years, the rate of new HIV infections has been stably decreasing worldwide [94], so that we might also expect decreasing frequency of thyroid complications related to HAART therapy. However, alternative novel therapies are also being developed that act on $\mathrm{T}$ and $\mathrm{B}$ cell compartments simultaneously followed by repopulation, which may also be associated with induced autoimmune disorders.

\section{Disclosure Statement}

J.J. is Wellcome Trust funded (grant number RG79413). 


\section{References}

1 Prummel MF, Laurberg P. Interferon-alpha and autoimmune thyroid disease. Thyroid. 2003 Jun;13(6):547-51.

2 Atkins MB, Mier JW, Parkinson DR, Gould JA, Berkman EM, Kaplan MM. Hypothyroidism after treatment with interleukin-2 and lymphokine-activated killer cells. N Engl J Med. 1988 Jun;318(24):1557-63.

3 Badros AZ, Siegel E, Bodenner D, Zangari M, Zeldis J, Barlogie B, et al. Hypothyroidism in patients with multiple myeloma following treatment with thalidomide. Am J Med. 2002 Apr;112(5):412-3.

4 Loh KC. Amiodarone-induced thyroid disorders: a clinical review. Postgrad Med J. 2000 Mar;76(893):133-40

5 Hancock SL, McDougall IR, Constine LS Thyroid abnormalities after therapeutic external radiation. Int J Radiat Oncol Biol Phys. 1995 Mar;31(5):1165-70.

6 Lazarus JH. The effects of lithium therapy on thyroid and thyrotropin-releasing hormone. Thyroid. 1998 Oct;8(10):909-13.

7 Smit JW, Stokkel MP, Pereira AM, Romijn JA, Visser TJ. Bexarotene-induced hypothyroidism: bexarotene stimulates the peripheral metabolism of thyroid hormones. J Clin Endocrinol Metab. 2007 Jul;92(7):2496-9.

8 Joshi MN, Whitelaw BC, Palomar MT, Wu Y, Carroll PV. Immune checkpoint inhibitorrelated hypophysitis and endocrine dysfunction: clinical review. Clin Endocrinol (Oxf). 2016 Sep;85(3):331-9.

9 Hamnvik OP, Larsen PR, Marqusee E. Thy roid dysfunction from antineoplastic agents. J Natl Cancer Inst. 2011 Nov;103(21):1572-87.

10 Illouz F, Braun D, Briet C, Schweizer U, Rodien P. Endocrine side-effects of anti-cancer drugs: thyroid effects of tyrosine kinase inhibitors. Eur J Endocrinol. 2014 Sep;171(3): R91-9.

11 Weetman A. Immune reconstitution syndrome and the thyroid. Best Pract Res Clin Endocrinol Metab. 2009 Dec;23(6):693-702.

12 Pariani N, Willis M, Muller I, Healy S, Nasser T, McGowan A, et al. Alemtuzumab-Induced Thyroid Dysfunction Exhibits Distinctive Clinical and Immunological Features. J Clin Endocrinol Metab. 2018 Aug;103(8):3010-8.

13 Daniels GH, Vladic A, Brinar V, Zavalishin I, Valente W, Oyuela P, et al. Alemtuzumab-related thyroid dysfunction in a phase 2 trial of patients with relapsing-remitting multiple sclerosis. J Clin Endocrinol Metab. 2014 Jan; 99(1):80-9.

14 Tuohy O, Costelloe L, Hill-Cawthorne G, Bjornson I, Harding K, Robertson N, et al. Alemtuzumab treatment of multiple sclerosis: long-term safety and efficacy. J Neurol Neurosurg Psychiatry. 2015 Feb;86(2):208-15.

15 Chen F, Day SL, Metcalfe RA, Sethi G, Kapembwa MS, Brook MG, et al. Characteristics of autoimmune thyroid disease occurring as a late complication of immune reconstitution in patients with advanced human immunodeficiency virus (HIV) disease. Medicine (Baltimore). 2005 Mar;84(2):98-106.

16 Gilquin J, Viard JP, Jubault V, Sert C, Kazatchkine MD. Delayed occurrence of Graves' disease after immune restoration with HAART. Highly active antiretroviral therapy. Lancet. 1998 Dec;352(9144):1907-8

17 Jubault V, Penfornis A, Schillo F, Hoen B, Izembart M, Timsit J, et al. Sequential occurrence of thyroid autoantibodies and Graves' disease after immune restoration in severely immunocompromised human immunodeficiency virus-1-infected patients. J Clin Endocrinol Metab. 2000 Nov;85(11):4254-7.

18 French MA, Lewin SR, Dykstra C, Krueger R, Price P, Leedman PJ. Graves' disease during immune reconstitution after highly active antiretroviral therapy for HIV infection: evidence of thymic dysfunction. AIDS Res Hum Retroviruses. 2004 Feb;20(2):157-62.

19 Knysz B, Bolanowski M, Klimczak M, Gladysz A, Zwolinska K. Graves' disease as an immune reconstitution syndrome in an HIV-1-positive patient commencing effective antiretroviral therapy: case report and literature review. Viral Immunol. 2006; 19(1):102-7.

20 Crum NF, Ganesan A, Johns ST, Wallace MR. Graves disease: an increasingly recognized immune reconstitution syndrome. AIDS. 2006 Feb;20(3):466-9.

21 Rasul S, Delapenha R, Farhat F, Gajjala J, Zahra SM. Graves' Disease as a Manifestation of Immune Reconstitution in HIV-Infected Individuals after Initiation of Highly Active Antiretroviral Therapy. Aids Res Treat. 2011; 2011:743597.

22 Ishiguro H, Yasuda Y, Tomita Y, Shinagawa T, Shimizu T, Morimoto T, et al. Long-term follow-up of thyroid function in patients who received bone marrow transplantation during childhood and adolescence. J Clin Endocrinol Metab. 2004 Dec;89(12):5981-6.

23 Kappos L, Li D, Calabresi PA, O’Connor P, Bar-Or A, Barkhof F, et al. Ocrelizumab in relapsing-remitting multiple sclerosis: a phase 2, randomised, placebo-controlled, multicentre trial. Lancet. 2011 Nov;378(9805):1779-87.

24 Memon AB, Javed A, Caon C, Srivastawa S, Bao F, Bernitsas E, et al. Long-term safety of rituximab induced peripheral B-cell depletion in autoimmune neurological diseases. PLoS One. 2018 Jan;13(1):e0190425.

25 Thompson SA, Jones JL, Cox AL, Compston DA, Coles AJ. B-cell reconstitution and BAFF after alemtuzumab (Campath-1H) treatment of multiple sclerosis. J Clin Immunol. 2010 Jan;30(1):99-105.

26 Coles AJ, Cox A, Le Page E, Jones J, Trip SA, Deans J, et al. The window of therapeutic opportunity in multiple sclerosis: evidence from monoclonal antibody therapy. J Neurol. 2006 Jan;253(1):98-108.

27 Hill-Cawthorne GA, Button T, Tuohy O, Jones JL, May K, Somerfield J, et al. Long term lymphocyte reconstitution after alemtuzum$\mathrm{ab}$ treatment of multiple sclerosis. J Neurol Neurosurg Psychiatry. 2012 Mar;83(3):298304.

28 Fleury S, Rizzardi GP, Chapuis A, Tambussi G, Knabenhans C, Simeoni E, et al. Long-term kinetics of T cell production in HIV-infected subjects treated with highly active antiretroviral therapy. Proc Natl Acad Sci USA. 2000 May;97(10):5393-8.

29 Hsiao LT, Liu JH, Yen CC, Wang WS, Fan FS, Chiou TJ, et al. Relapse of Graves' disease after successful allogeneic bone marrow transplantation. Bone Marrow Transplant. 2001 Dec; 28(12):1151-3.

30 Walsh M, Chaudhry A, Jayne D. Long-term follow-up of relapsing/refractory anti-neutrophil cytoplasm antibody associated vasculitis treated with the lymphocyte depleting antibody alemtuzumab (CAMPATH-1H). Ann Rheum Dis. 2008 Sep;67(9):1322-7.

31 Mohammad AJ, Smith RM, Chow YW, Chaudhry AN, Jayne DR. Alemtuzumab as Remission Induction Therapy in Behçet Disease: A 20-year Experience. J Rheumatol. 2015 Oct;42(10):1906-13.

32 Isaacs JD, Greer S, Sharma S, Symmons D, Smith M, Johnston J, et al. Morbidity and mortality in rheumatoid arthritis patients with prolonged and profound therapy-induced lymphopenia. Arthritis Rheum. 2001 Sep;44(9):1998-2008.

33 Lundin J, Porwit-MacDonald A, Rossmann ED, Karlsson C, Edman P, Rezvany MR, et al. Cellular immune reconstitution after subcutaneous alemtuzumab (anti-CD52 monoclonal antibody, CAMPATH-1H) treatment as first-line therapy for B-cell chronic lymphocytic leukaemia. Leukemia. 2004 Mar;18(3): 484-90.

34 Haynes R, Harden P, Judge P, Blackwell L, Emberson J, Landray MJ, et al.; 3C Study Collaborative Group. Alemtuzumab-based induction treatment versus basiliximab-based induction treatment in kidney transplantation (the 3C Study): a randomised trial. Lancet. 2014 Nov;384(9955):1684-90.

35 Kirk AD, Hale DA, Swanson SJ, Mannon RB. Autoimmune thyroid disease after renal transplantation using depletional induction with alemtuzumab. Am J Transplant. 2006 May;6(5 Pt 1):1084-5.

36 Cooles FA, Anderson AE, Drayton T, Harry RA, Diboll J, Munro L, et al. Immune reconstitution 20 years after treatment with alemtuzumab in a rheumatoid arthritis cohort: implications for lymphocyte depleting therapies. Arthritis Res Ther. 2016 Dec;18(1):302.

37 Muller I, Willis M, Healy S, Nasser T, Loveless $S$, Butterworth S, et al. Longitudinal characterization of autoantibodies to the thyrotropin receptor (TRAb) during alemtuzumab therapy: evidence that TRAb may precede thyroid dysfunction by many years. Thyroid. 2018 Dec;28(12):1682-93.
ETA Guidelines on Thyroid Dysfunction following Immune Reconstitution
Eur Thyroid J 2019;8:173-185 DOI: $10.1159 / 000500881$ 
38 Rees Smith B, McLachlan SM, Furmaniak J. Autoantibodies to the thyrotropin receptor. Endocr Rev. 1988 Feb;9(1):106-21.

39 Diana T, Krause J, Olivo PD, König J, Kanitz M, Decallonne B, et al. Prevalence and clinical relevance of thyroid stimulating hormone receptor-blocking antibodies in autoimmune thyroid disease. Clin Exp Immunol. 2017 Sep; 189(3):304-9.

40 Vanderpump MP, Tunbridge WM, French JM, Appleton D, Bates D, Clark F, et al. The incidence of thyroid disorders in the community: a twenty-year follow-up of the Whickham Survey. Clin Endocrinol (Oxf). 1995 Jul; 43(1):55-68.

41 Al-Fiar FZ, Colwill R, Lipton JH, Fyles G, Spaner D, Messner H. Abnormal thyroid stimulating hormone (TSH) levels in adults following allogeneic bone marrow transplants. Bone Marrow Transplant. 1997 May; 19(10):1019-22.

42 Bhatia S, Armenian SH, Landier W. How I monitor long-term and late effects after blood or marrow transplantation. Blood. 2017 Sep; 130(11):1302-14

43 Farhadfar N, Stan MN, Shah P, Sonawane V, Hefazi MT, Murthy HS, et al. Thyroid dysfunction in adult hematopoietic cell transplant survivors: risks and outcomes. Bone Marrow Transplant. 2018 Aug;53(8):97782.

44 Aldouri MA, Ruggier R, Epstein O, Prentice HG. Adoptive transfer of hyperthyroidism and autoimmune thyroiditis following allogeneic bone marrow transplantation for chronic myeloid leukaemia. Br J Haematol. 1990 Jan;74(1):118-9.

45 Karthaus M, Gabrysiak T, Brabant G, Prahst A, Link H, Soudah B, et al. Immune thyroiditis after transplantation of allogeneic CD34+ selected peripheral blood cells. Bone Marrow Transplant. 1997 Oct;20(8):697-9.

46 Berisso GA, van Lint MT, Bacigalupo A, Marmont AM. Adoptive autoimmune hyperthyroidism following allogeneic stem cell transplantation from an HLA-identical sibling with Graves' disease. Bone Marrow Transplant. 1999 May;23(10):1091-2.

47 Takeshita A, Shinjo K, Ohno R. Graves disease after bone marrow transplantation. Ann Intern Med. 1999 Jul;131(2):157.

48 Atkins D, Best D, Briss PA, Eccles M, FalckYtter Y, Flottorp S, et al.; GRADE Working Group. Grading quality of evidence and strength of recommendations. BMJ. 2004 Jun; 328(7454): 1490.

49 Guyatt GH, Cook DJ, Jaeschke R, Pauker SG, Schünemann HJ. Grades of recommendation for antithrombotic agents: American College of Chest Physicians Evidence-Based Clinical Practice Guidelines (8th Edition). Chest. 2008 Jun;133(6 Suppl):123S-31S.

50 Coles AJ, Wing M, Smith S, Coraddu F, Greer $\mathrm{S}$, Taylor C, et al. Pulsed monoclonal antibody treatment and autoimmune thyroid disease in multiple sclerosis. Lancet. 1999 Nov; 354(9191):1691-5.
51 Haugen BR, Alexander EK, Bible KC, Doherty GM, Mandel SJ, Nikiforov YE, et al. 2015 American Thyroid Association Management Guidelines for Adult Patients with Thyroid Nodules and Differentiated Thyroid Cancer: The American Thyroid Association Guidelines Task Force on Thyroid Nodules and Differentiated Thyroid Cancer. Thyroid. 2016 Jan;26(1):1-133.

52 Gharib H, Papini E, Garber JR, Duick DS, Harrell RM, Hegedüs L, et al.; AACE/ACE/ AME Task Force on Thyroid Nodules. American Association of Clinical Endocrinologists, American College of Endocrinology, and Associazione Medici Endocrinologi Medical Guidelines for Clinical Practice for the Diagnosis and Management of Thyroid Nodules-2016 Update. Endocr Pract. 2016 May; 22(5 Supplement 1):622-39.

53 Russ G, Bonnema SJ, Erdogan MF, Durante C, Ngu R, Leenhardt L. European Thyroid Association Guidelines for Ultrasound Malignancy Risk Stratification of Thyroid Nodules in Adults: the EU-TIRADS. Eur Thyroid J. 2017 Sep;6(5):225-37.

54 EMA. Lemtrada: EPAR-Product-Information, 2018. Available from: https://www.ema. europa.eu/documents/product-information/ lemtrada-epar-product-information_en.pdf.

55 Silva GA, Andrade MC, Sugui DA, Nunes RF, Pinto JF, Eyer Silva WA, et al. Association between antiretrovirals and thyroid diseases: a cross-sectional study. Arch Endocrinol Metab. 2015 Apr;59(2):116-22.

56 Aberg JA, Gallant JE, Ghanem KG, Emmanuel $\mathrm{P}$, Zingman BS, Horberg MA; Infectious Diseases Society of America. Primary care guidelines for the management of persons infected with HIV: 2013 update by the HIV Medicine Association of the Infectious Diseases Society of America. Clin Infect Dis. 2014 Jan;58(1):1-10.

57 Havrdova E, Arnold DL, Cohen JA, Hartung HP, Fox EJ, Giovannoni G, et al.; CARE-MS I and CAMMS03409 Investigators. Alemtuzumab CARE-MS I 5-year follow-up: durable efficacy in the absence of continuous MS therapy. Neurology. 2017 Sep;89(11):1107-16.

58 Coles AJ, Cohen JA, Fox EJ, Giovannoni G, Hartung HP, Havrdova E, et al.; CARE-MS II and CAMMS03409 Investigators. Alemtuzumab CARE-MS II 5-year follow-up: efficacy and safety findings. Neurology. 2017 Sep; 89(11):1117-26.

59 Coles AJ, Twyman CL, Arnold DL, Cohen JA, Confavreux C, Fox EJ, et al.; CARE-MS II investigators. Alemtuzumab for patients with relapsing multiple sclerosis after diseasemodifying therapy: a randomised controlled phase 3 trial. Lancet. 2012 Nov;380(9856): 1829-39.

60 Cohen JA, Coles AJ, Arnold DL, Confavreux C, Fox EJ, Hartung HP, et al.; CARE-MS I investigators. Alemtuzumab versus interferon beta $1 \mathrm{a}$ as first-line treatment for patients with relapsing-remitting multiple sclerosis: a randomised controlled phase 3 trial. Lancet. 2012 Nov;380(9856):1819-28.
61 Miller T, Habek M, Coles A. Analysis of data from RRMS alemtuzumab-treated patients in the clinical program to evaluate incidence rates of malignancy. European Committee for Treatment and Research in Multiple Sclerosis (ECTRIMS) Meeting. Boston, MA, USA; September 10-13, 2014.

62 Lecumberri B, Arnold D, Cohen J. Detection of thyroid malignancies in alemtuzumabtreated patients in the multiple sclerosis clinical development program. Mult Scler. 2015; 21 S11:1117.

63 Weetman AP. Thyroid abnormalities. Endocrinol Metab Clin North Am. 2014 Sep;43(3): 781-90.

64 Simard EP, Shiels MS, Bhatia K, Engels EA. Long-term cancer risk among people diagnosed with AIDS during childhood. Cancer Epidemiol Biomarkers Prev. 2012 Jan;21(1): $148-54$

65 Cobucci RN, Lima PH, de Souza PC, Costa VV, Cornetta MC, Fernandes JV, et al. Assessing the impact of HAART on the incidence of defining and non-defining AIDS cancers among patients with HIV/AIDS: a systematic review. J Infect Public Health. 2015 Jan-Feb;8(1):1-10.

66 Mukhtar F, Ilozumba M, Utuama O, Cimenler O. Change in Pattern of Secondary Cancers After Kaposi Sarcoma in the Era of Antiretroviral Therapy. JAMA Oncol. 2018 Jan; 4(1):48-53.

67 Ji Y, Lu H. Malignancies in HIV-Infected and AIDS Patients. Adv Exp Med Biol. 2017;1018: 167-79.

68 Lin JS, Bowles EJ, Williams SB, Morrison CC Screening for Thyroid Cancer: Updated Evidence Report and Systematic Review for the US Preventive Services Task Force. JAMA. 2017 May;317(18):1888-903.

69 Weetman AP. Graves' disease following immune reconstitution or immunomodulatory treatment: should we manage it any differently? Clin Endocrinol (Oxf). 2014 May;80(5):629-32.

70 Decallonne B, Bartholomé E, Delvaux V, D’haeseleer M, El Sankari S, Seeldrayers P, et al. Thyroid disorders in alemtuzumab-treated multiple sclerosis patients: a Belgian consensus on diagnosis and management. Acta Neurol Belg. 2018 Jun;118(2):153-9.

71 Krassas GE, Poppe K, Glinoer D. Thyroid function and human reproductive health. Endocr Rev. 2010 Oct;31(5):702-55.

72 Korevaar TI, Medici M, Visser TJ, Peeters RP. Thyroid disease in pregnancy: new insights in diagnosis and clinical management. Nat Rev Endocrinol. 2017 Oct;13(10):610-22.

73 Ross DS, Burch HB, Cooper DS, Greenlee MC, Laurberg P, Maia AL, et al. 2016 American Thyroid Association Guidelines for Diagnosis and Management of Hyperthyroidism and Other Causes of Thyrotoxicosis. Thyroid. 2016 Oct;26(10):1343-421.

74 Erdoğan MF, Anil C, Cesur M, Başkal N, Erdoğan G. Color flow Doppler sonography for the etiologic diagnosis of hyperthyroidism. Thyroid. 2007 Mar;17(3):223-8. 
75 Kim TK, Lee EJ. The value of the mean peak systolic velocity of the superior thyroidal artery in the differential diagnosis of thyrotoxicosis. Ultrasonography. 2015 Oct;34(4):292-6.

76 Kahaly GJ, Bartalena L, Hegedüs L, Leenhardt L, Poppe K, Pearce SH. 2018 European Thyroid Association Guideline for the Management of Graves' Hyperthyroidism. Eur Thyroid J. 2018 Aug;7(4):167-86.

77 Cossburn M, Pace AA, Jones J, Ali R, Ingram G, Baker K, et al. Autoimmune disease after alemtuzumab treatment for multiple sclerosis in a multicenter cohort. Neurology. 2011 Aug; 77(6):573-9.

78 Zhyzhneuskaya S, Addison C, Tsatlidis V, Weaver JU, Razvi S. The Natural History of Subclinical Hyperthyroidism in Graves' Disease: The Rule of Thirds. Thyroid. 2016 Jun; 26(6):765-9.

79 McLachlan SM, Rapoport B. Thyrotropinblocking autoantibodies and thyroid-stimulating autoantibodies: potential mechanisms involved in the pendulum swinging from hypothyroidism to hyperthyroidism or vice versa. Thyroid. 2013 Jan;23(1):14-24.

80 Abraham P, Avenell A, McGeoch SC, Clark LF, Bevan JS. Antithyroid drug regimen for treating Graves' hyperthyroidism. Cochrane Database Syst Rev. 2010 Jan;(1):CD003420.

81 Jonklaas J, Bianco AC, Bauer AJ, Burman KD, Cappola AR, Celi FS, et al.; American Thyroid Association Task Force on Thyroid Hormone Replacement. Guidelines for the treatment of hypothyroidism: prepared by the american thyroid association task force on thyroid hormone replacement. Thyroid. 2014 Dec; 24(12):1670-751.

82 Parsa AA, Bhangoo A. HIV and thyroid dysfunction. Rev Endocr Metab Disord. 2013 Jun;14(2):127-31.

83 Lazarus J, Brown RS, Daumerie C, Hubalewska-Dydejczyk A, Negro R, Vaidya B. 2014 European thyroid association guidelines for the management of subclinical hypothyroidism in pregnancy and in children. Eur Thyroid J. 2014 Jun;3(2):76-94.

84 Alexander EK, Pearce EN, Brent GA, Brown RS, Chen H, Dosiou C, et al. 2017 Guidelines of the American Thyroid Association for the Diagnosis and Management of Thyroid Disease During Pregnancy and the Postpartum. Thyroid. 2017 Mar;27(3):315-89.

85 Bartalena L, Pinchera A, Marcocci C. Management of Graves' ophthalmopathy: reality and perspectives. Endocr Rev. 2000 Apr; 21(2):168-99.

86 Lazarus JH. Epidemiology of Graves' orbitopathy (GO) and relationship with thyroid disease. Best Pract Res Clin Endocrinol Metab. 2012 Jun;26(3):273-9.

87 Laurberg P, Berman DC, Bülow Pedersen I, Andersen S, Carlé A. Incidence and clinical presentation of moderate to severe graves' orbitopathy in a Danish population before and after iodine fortification of salt. J Clin Endocrinol Metab. 2012 Jul;97(7):2325-32.

88 Tanda ML, Piantanida E, Liparulo L, Veronesi G, Lai A, Sassi L, et al. Prevalence and natural history of Graves' orbitopathy in a large series of patients with newly diagnosed graves' hyperthyroidism seen at a single center. J Clin Endocrinol Metab. 2013 Apr;98(4): 1443-9.

89 Edmunds MR, Mellington F, Ford RL, Torlinska B, Manavi K, Boelaert K. Clinical challenges of thyroid eye disease in HIV-positive patients on highly active antiretroviral therapy. J Clin Endocrinol Metab. 2015 Mar; 100(3):779-87.

90 Bartalena L, Baldeschi L, Boboridis K, Eckstein A, Kahaly GJ, Marcocci C, et al.; European Group on Graves' Orbitopathy (EUGOGO). The 2016 European Thyroid Association/European Group on Graves' Orbitopathy Guidelines for the Management of Graves' Orbitopathy. Eur Thyroid J. 2016 Mar;5(1): 9-26.

91 Mulero P, Midaglia L, Montalban X. Ocrelizumab: a new milestone in multiple sclerosis therapy. Ther Adv Neurol Disorder. 2018 May;11:1756286418773025.

92 Cook S, Leist T, Comi G, Montalban X, Giovannoni G, Nolting A, et al. Safety of cladribine tablets in the treatment of patients with multiple sclerosis: an integrated analysis. Mult Scler Relat Disord. 2019 Apr;29:157-67.

93 Graf J, Aktas O, Rejdak K, Hartung HP. Monoclonal Antibodies for Multiple Sclerosis: an Update. BioDrugs. 2019 Feb;33(1):61-78.

94 UNAIDS. Trend of new HIV infections. AIDSinfo 2018. Available from: http://aidsinfo. unaids.org.
ETA Guidelines on Thyroid Dysfunction following Immune Reconstitution
Eur Thyroid J 2019;8:173-185 DOI: $10.1159 / 000500881$ 